Article

\title{
Organic Solvent Sensors Using Polymer-Dispersed Liquid Crystal Films with a Pillar Pattern
}

\author{
Chia-Yi Huang ${ }^{1}(\mathbb{D}$ and Shih-Hung Lin $2,3, * \mathbb{D}$ \\ 1 Department of Applied Physics, Tunghai University, Taichung 40704, Taiwan; chiayihuang@thu.edu.tw \\ 2 Department of Optometry, Chung Shan Medical University, Taichung 40201, Taiwan \\ 3 Department of Ophthalmology, Chung Shan Medical University Hospital, Taichung 40201, Taiwan \\ * Correspondence: shihhung@csmu.edu.tw
}

check for updates

Citation: Huang, C.-Y.; Lin, S.-H Organic Solvent Sensors Using Polymer-Dispersed Liquid Crystal Films with a Pillar Pattern. Polymers 2021, 13, 2906. https://doi.org/ $10.3390 /$ polym 13172906

Academic Editors: Tibor Toth-Katona and Istvan Janossy

Received: 6 August 2021

Accepted: 26 August 2021

Published: 29 August 2021

Publisher's Note: MDPI stays neutral with regard to jurisdictional claims in published maps and institutional affiliations.

Copyright: (c) 2021 by the authors. Licensee MDPI, Basel, Switzerland. This article is an open access article distributed under the terms and conditions of the Creative Commons Attribution (CC BY) license (https:// creativecommons.org/licenses/by/ $4.0 /)$.

\begin{abstract}
An organic solvent sensor of polymer-dispersed liquid crystals (PDLCs) film is fabricated by a combination of tri-functional monomers and LCs. When the patterned PDLC film comes into contact with the organic solvent, the organic solvent will penetrate into the film to induce the orientation of the liquid crystals, which will change from an ordered to a disordered state, which causes the PDLC film to scatter incident light. The experiment used acetone and ethanol as the organic solvents of interest. The results show that the patterned PDLC film has a stronger response to acetone than to ethanol. Based on the difference in the intensity of light scattering and the response time of the patterned PDLC film to different organic solvents, the results can be used to identify and recognize different types of organic solvents.
\end{abstract}

Keywords: sensor; polymer-dispersed liquid crystal (PDLC); organic solvent

\section{Introduction}

The combination of polymers and liquid crystals (LCs) can be classified into different configurations via the properties of the polymers, including LC cells with photoconductive polymer films [1,2], LC cells with polymer structures [3,4], polymer-stabilized LCs (PSLCs) [5-7], polymer-dispersed LCs (PDLCs) [8-18], and LC elastomers [19]. PDLC films that comprise LC droplets dispersed in polymers are formed due to the light-induced phase separation in the precursors of the PDLCs. The PDLC films are opaque at zero voltage because the mismatching of the refractive indices of the LC droplets and polymers scatter the lights that are incident to the films [8-14]. Application of voltages to the PDLC films makes them transparent due to the matching of the refractive indices of the LC droplets and polymers [8-14]. The transmittances of the PDLC films can be modulated by external voltages, and polarizers are not required at the transmittance modulation. Therefore, PDLC films have potential in developing electro-optic devices such as displays [8-12], lenses [13,14], sensors [15,16], gratings [17,18], lasers [20-22], and light modulators [23-25].

The cross-linked polymers consisting of mono- and bi-functional monomers have smaller anchoring energies than those consisting of tri-functional monomers, so the monoand bi-functional monomers are widely used to fabricate the PDLC films with small operating voltages and large contrast ratios. Therefore, the PDLC films that involve monoand bi-functional monomers can be used for displays, electric curtains, and electronic labels. The cross-linked polymers consisting of tri-functional monomers have excellent mechanical properties against compression, stretching, and bending. Therefore, it is of great interest to researchers to develop PDLC films.

This work used a tri-functional monomer and LCs to fabricate a PDLC film via photopolymerization, and the film was patterned by photolithography and imprinting. As the PDLC film with a pillar pattern is exposed to acetone, acetone will penetrate into the film to induce the disordered orientation of LC molecules in acetone, resulting in the scattering of incident light. A PDLC film without a pillar pattern was used to evaluate the 
response of the PDLC film with the pillar pattern to acetone. The PDLC film with the pillar pattern had a lager change in its transmittance than the PDLC film without a pillar pattern after the two films were exposed to acetone. The PDLC film with the pillar pattern had a weaker response to ethanol than to acetone. Therefore, the PDLC film with the pillar pattern can be used to develop solvent sensors and has potential in sensing gas.

\section{Materials and Methods}

Figure 1a presents the schematic drawing of a glass substrate with a photoresist grid pattern. This work used photolithography to make a grid pattern on glass substrates. A photoresist (EPG516, Everlight Chemical Industrial Co., Taiwan) was spin-coated on a glass substrate with an area of $2 \mathrm{~cm} \times 2 \mathrm{~cm}$. The glass substrate with the photoresist layer was put on a hot plate for soft baking. A grid pattern on a photomask was transferred onto the photoresist layer under UV irradiation. The irradiated photoresist layer was developed using a developer (EPD48, Everlight Chemical Industrial Co., Tainan, Taiwan) and then was fixed using water. The photoresist grid pattern was obtained following the fixing process. The photoresist grid pattern was deposited on the glass substrate and had a line width and thickness of $200 \mu \mathrm{m}$ and $11 \mu \mathrm{m}$, respectively. Polyimide was coated on the glass substrates with the photoresist patterns and rubbed to generate anchoring in the polyimide surface. Each of the empty cells was fabricated by the glass substrate with polyimide-coated photoresist patterns and another glass substrate with a rubbed polyimide layer. The two glass substrates were separated by two plastic spacers with a thickness of $25 \mu \mathrm{m}$ or $50 \mu \mathrm{m}$. A PDLC precursor consisted of a nematic LC HTW114200-100 (65 wt.\%, Fusol Material Co., Tainan, Taiwan), monomer TMPTA (33 wt.\%, Sigma-Aldrih, St. Louis, MI, USA), and photoinitiator IRG 184 (2 wt.\%, Ciba, Basel, Switzerland). The LC has extraordinary and ordinary refractive indices of 1.77 and 1.51 , respectively, at $25^{\circ} \mathrm{C}$. The TMPTA has a refractive index of 1.47 at $25^{\circ} \mathrm{C}$. The empty cells were filled with the PDLC precursor, and then the PDLC precursor was cured using UV light with a center wavelength of $365 \mathrm{~nm}$ and an intensity of $5 \mathrm{~mW} / \mathrm{cm}^{2}$ for $50 \mathrm{~min}$. The temperature of the cells was kept at $13{ }^{\circ} \mathrm{C}$ during the curing. After the two glass substrates were separated and removed from the cell, the patterned PDLC film could be directly taken out and used. Figure $1 \mathrm{~b}$ presents the image of the patterned PDLC film with an area of $1.5 \mathrm{~cm} \times 1.5 \mathrm{~cm}$. Figure $1 \mathrm{c}$, d shows the SEM image of the patterned PDLC film. In Figure 1c, the $200 \mu \mathrm{m} \times 200 \mu \mathrm{m}$ square is the PDLC pillar pattern. The cross-section of the patterned PDLC film presents the thickness of the film, which was about $40-50 \mu \mathrm{m}$, and the height of the pillar pattern was about $10 \mu \mathrm{m}$, as shown in Figure 1d.

Each of the patterned and planar PDLC films was framed using a glass plate with a square hole with a side length of $1.0 \mathrm{~cm}$, as presented in Figure 2a. Organic solvents with a volume of $10 \mu \mathrm{L}$ were dropped on these films. A probe light from a He-Ne laser with a wavelength of $632.8 \mathrm{~nm}$ was used to study the effect of organic solvents on the PDLC films, as presented in Figure 2b. The probe light was normally incident to each of these films, and a lens was placed behind that film to collect the light that passes through them. A power meter (NOAII, Ophir, Jerusalem, Israel) was placed behind the lens to detect the intensity of the transmitting light. 

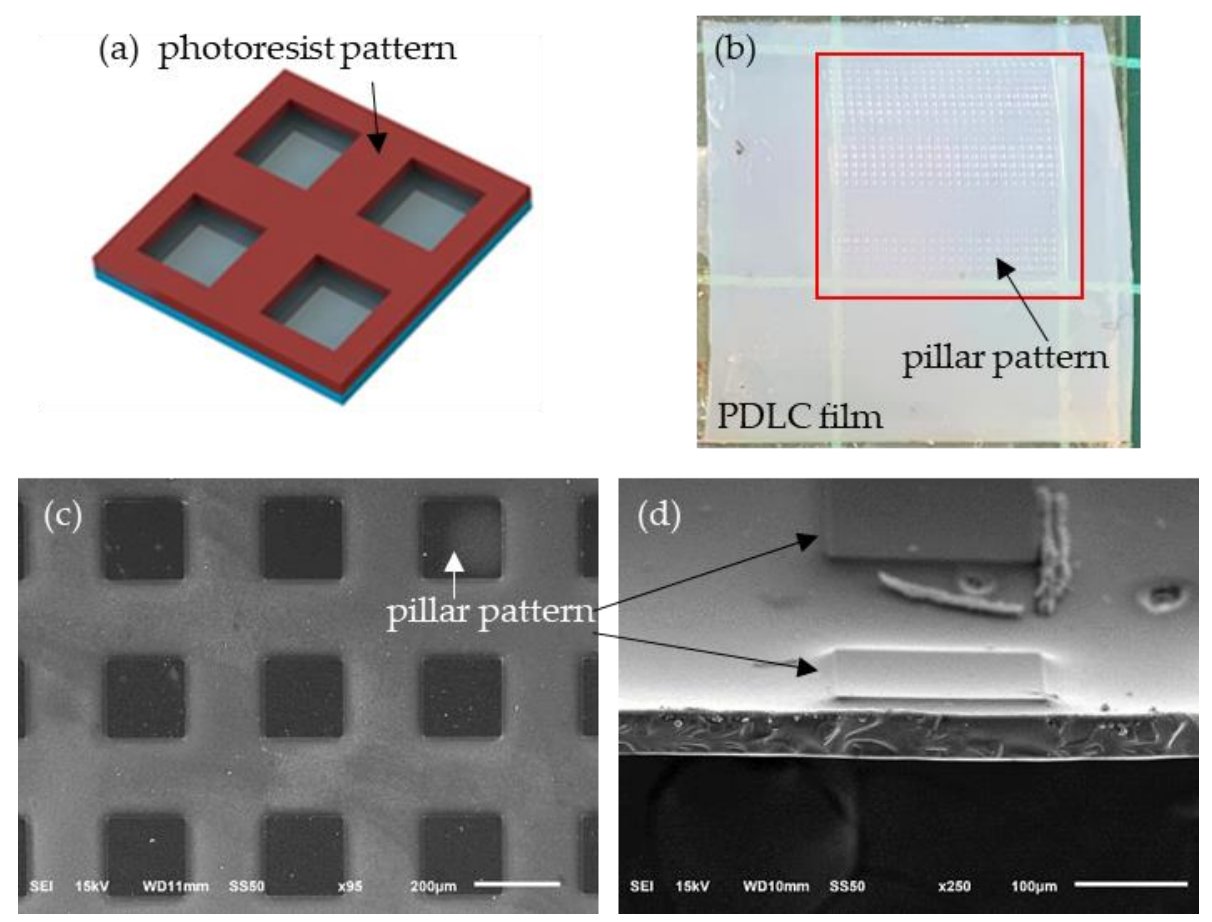

Figure 1. (a) Schematic drawing of glass substrate with photoresist pattern; (b) image of patterned PDLC film; (c) SEM image of top view of patterned PDLC film; (d) SEM image of section view of patterned PDLC film.
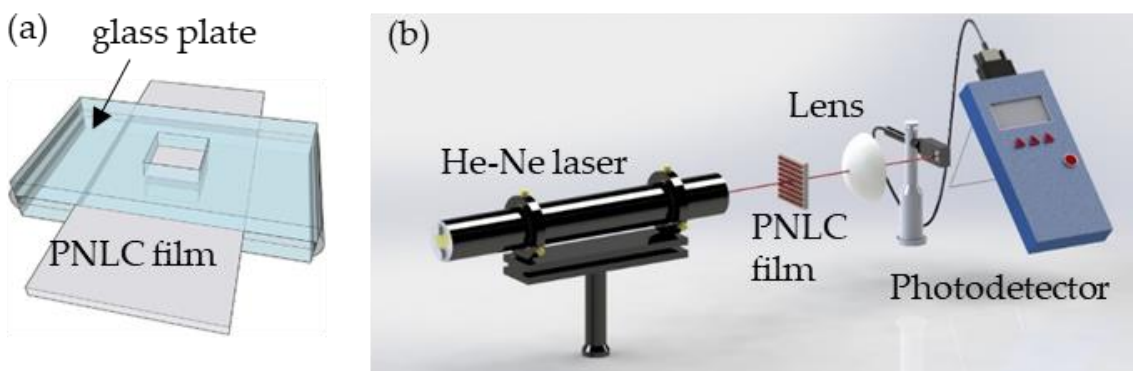

Figure 2. (a) PDLC film framed by glass plate with a square hole with a side length of $1.0 \mathrm{~cm}$; (b) measurement of transmittances of patterned and planar PDLC films that are exposed to organic solvents.

\section{Results and Discussion}

Figure 3a,d depict polarizing microscopic images of patterned PDLC films with planar alignment. Figure 3 a shows that when the rubbing direction and the polarizer are at an angle of 0 degree, because the LC orientation is parallel to the direction of the polarizer, the incident light cannot pass through the analyzer, and the image of patterned PDLC film exhibit a dark state. When the rubbing direction and the polarizer have an angle of 45 degrees, the LC orientation was not parallel to the direction of the polarizer, causing part of the light to pass through the analyzer, and the image of patterned PDLC film appears in a bright state, as shown in Figure 3b. Figure $3 \mathrm{c}$ shows the PDLC film without exposure to acetone. The alignment direction of patterned PDLC film was at a 45-degree angle with the polarizer, and the LC molecules were arranged in an orderly nematic phase. When the PDLC film was exposed to acetone, the binding force between the molecules in the acetone was reduced, and the overall ordered molecules were split into the LC droplets of the disordered phase. The disordered LC droplets caused strong light scattering, as shown in Figure 3d. 

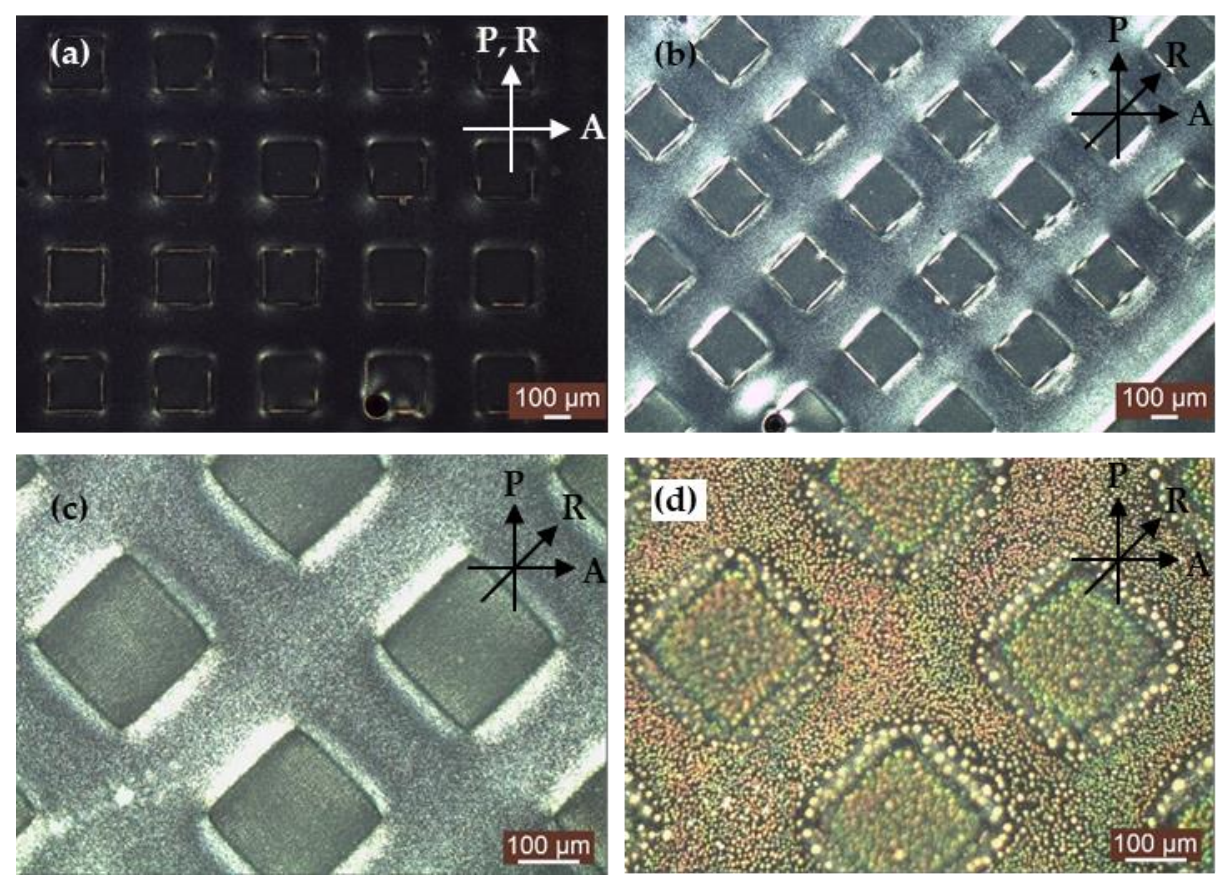

Figure 3. Microscopic images of patterned PDLC films under crossed polarizers at (a) R//P; (b) $45^{\circ}$ between $\mathrm{R}$ and $\mathrm{P}$; (c) without acetone; (d) with acetone. $\mathrm{P}$ and A denote the transmission axes of the polarizer and analyzer, respectively, and $\mathrm{R}$ denotes the rubbing direction.

A nematic LC cell was placed in a polarizing optical microscope under crossed polarizers, and a camera was used to capture the dynamic images of the nematic LC that was exposed to acetone. Figure 4 presents the dynamic images of the nematic LC that was exposed to acetone by a polarizing optical microscope under crossed polarizers. The leftmost image of Figure 4 presents that the dark area refers to acetone, and the bright area stands for the LC crystalline. Throughout the time course, when acetone was distributed over the nematic LCs, acetone existed between the LC molecules. Therefore, the reduced intermolecular force of the LC molecules loosened the LC crystalline. That explains why the bright area turns to dark-because the LCs from a liquid crystalline phase changed from ordered to disordered. Figure 4 verifies that the interaction mechanism of the nematic LCs and acetone was the phase transition of the LCs from a liquid crystalline phase to a disordered phase in the presence of acetone.

\section{Time}
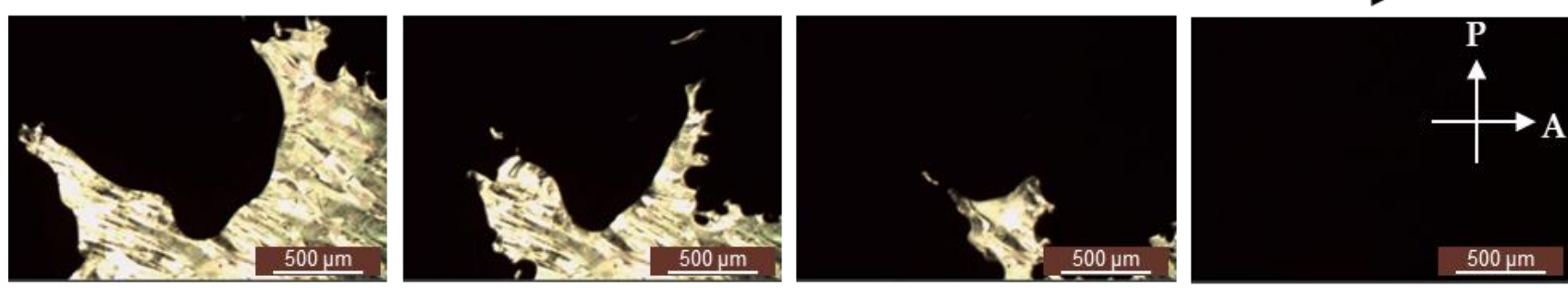

Figure 4. Dynamic images of nematic LCs that were exposed to acetone by a polarizing optical microscope under crossed polarizers.

Figure $5 \mathrm{a}-\mathrm{c}$ demonstrates the images of a patterned PDLC film before exposure to acetone, in exposure to acetone, and after the complete volatilization of acetone. The four corners of the patterned PDLC film were fixed on a metal plate with a circular hole with a diameter of $1 \mathrm{~cm}$ using $3 \mathrm{M}$ tapes. The letter " $\mathrm{A}$ " was printed on a paper, and the paper was placed behind the metal plate. Figure 5a presents that the letter-A image was clear 
before the patterned PDLC film was exposed to acetone. Figure $5 \mathrm{~b}$ displays that the letter-A image was unclear when the patterned PDLC film was exposed to acetone. The unclear image arose because acetone disturbs the orientation of the LCs of the patterned PDLC film. Figure $5 \mathrm{~d}$,e demonstrates the mechanism of the patterned PDLC film in acetone. When the PDLC film was not exposed to organic solvent, the LC molecules exhibited a more ordered orientation, as shown in Figure 5d. Figure 5e presents that the PDLC film was exposed to organic solvent where the organic solvent penetrates into the PDLC film. The organic solvent molecules penetrated and accumulated in the cross-linked polymer, followed by disturbing the alignment of the LC molecules, which resulted in disordering the orientations of the LC molecules. The disordered orientations of LC molecules induced the light scattering. In other words, the intermolecular force of the LCs was decreased in the acetone. The decreased intermolecular force disordered the orientations of the LC molecules, scattering the light that blurs the A of Figure $5 \mathrm{~b}$. When the volatilization of acetone was more significant than the penetration of acetone in the PDLC film, the LCs returned to the initial orientations due to the loss of the interference of acetone molecules and the original alignment of the cross-linked polymer. Therefore, the letter-A image in Figure $5 \mathrm{c}$ was clear after the complete volatilization of acetone.
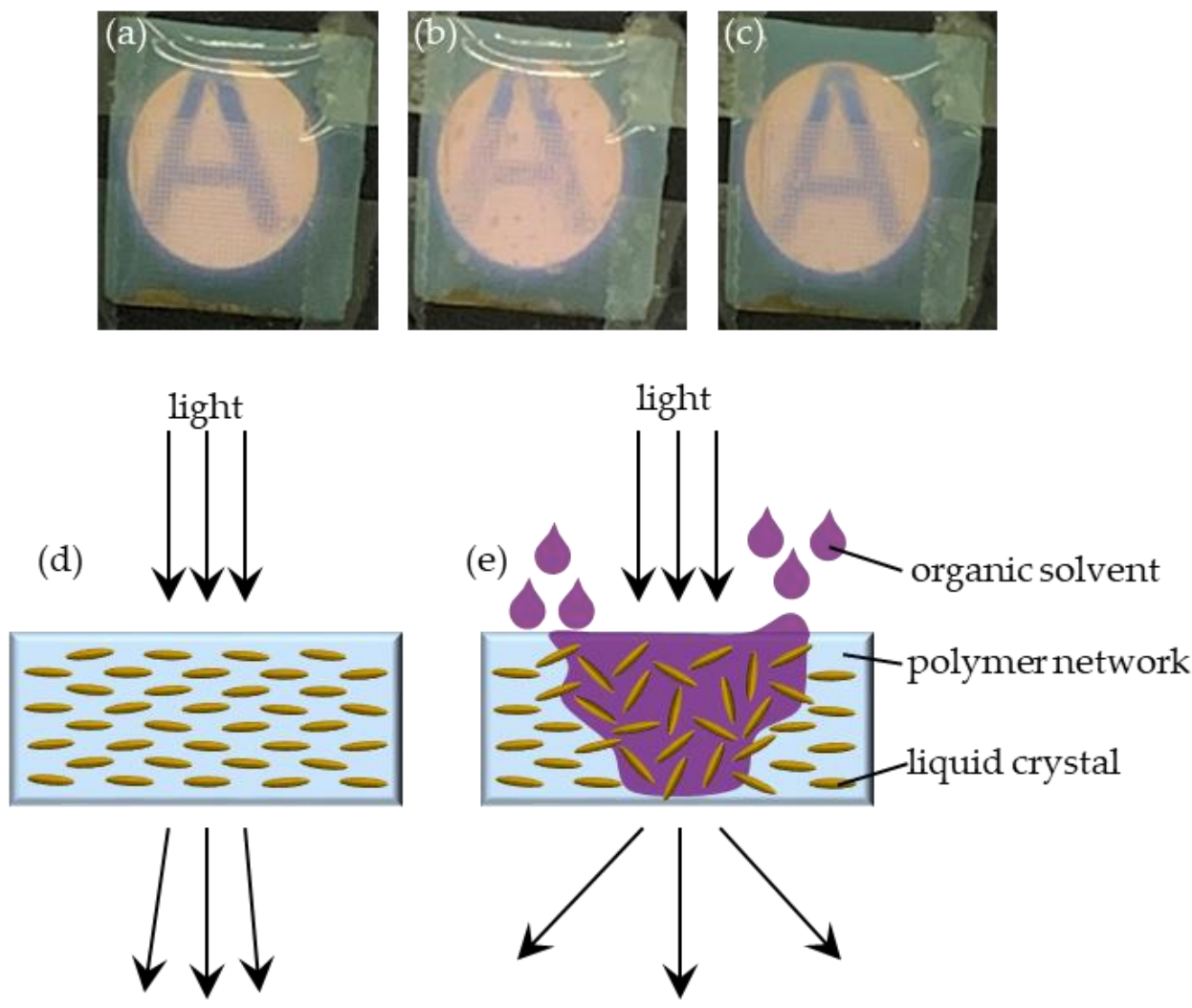

Figure 5. Images of patterned PDLC film (a) before exposure to acetone; (b) during exposure to acetone; (c) after complete volatilization of acetone; $(\mathbf{d}, \mathbf{e})$ mechanism of patterned PDLC film in organic solvent.

Figure 6 presents the time-dependent transmittance curve $T(t)$ of the PDLC films with different thicknesses and surfaces that were exposed to acetone. The transmittances of the films were defined as a ratio of the intensity of the light that passes through the film to the light that is incident to the film. When the PDLC film was exposed to acetone, the penetration of acetone into film was greater than the volatilization of acetone. Acetone disturbs the original orientation of LC molecules, causing the LC orientation to become disordered. 


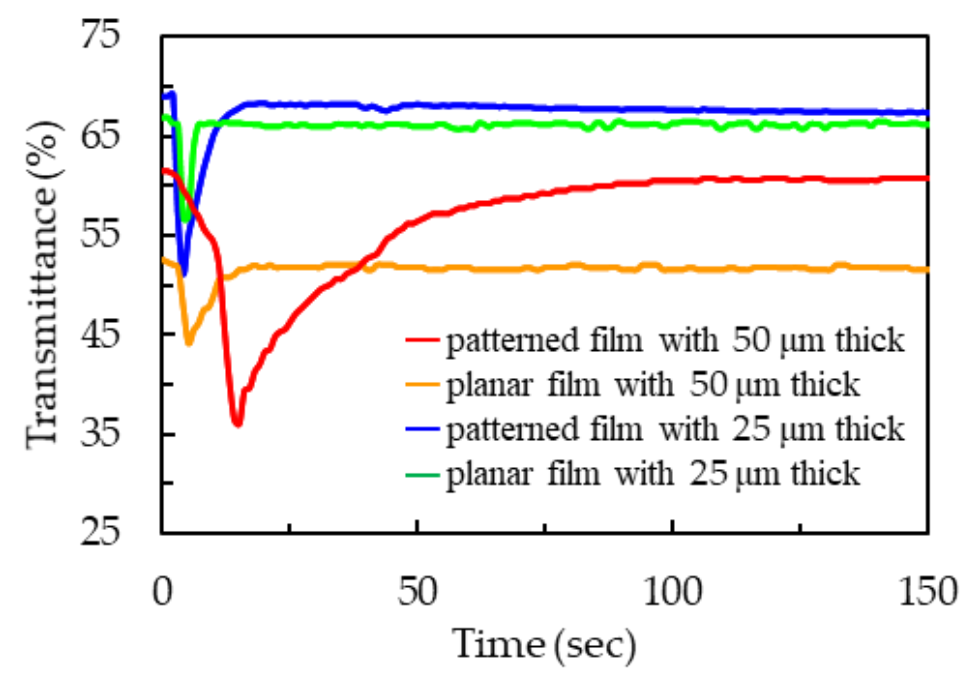

Figure 6. Time-dependent transmittance curves of the PDLC films with different thicknesses and surfaces that were exposed to acetone.

The red line in Figure 6 presents the time-dependent transmittance curve $T(t)$ of the patterned PDLC film with a thickness of $50 \mu \mathrm{m}$ that is exposed to acetone. When the penetration of acetone into film was greater than the volatilization of acetone, the transmittance of the patterned PDLC film decreased from its initial value of $61.5 \%$ to a minimum value of $36.1 \%$ in a short duration from $t=0 \mathrm{~s}$ to $\mathrm{t}=15 \mathrm{~s}$. The scattering of the PDLC film resulted in a difference in transmittance of $25.4 \%$. Subsequently, the volatilization of acetone was more significant than the penetration of acetone, and the transmittance increased from the minimum value to the initial value in a long duration from $t=15 \mathrm{~s}$ to $t=96 \mathrm{~s}$. The time for the decrease/increase in the transmittance from the initial/minimum value to the minimum/initial value was $15 / 81 \mathrm{~s}$, which was named the penetration/volatilization time of acetone. The orange line in Figure 6 presents the time-dependent transmittance curve $T(t)$ of the planar PDLC film with a thickness of $50 \mu \mathrm{m}$ that was exposed to acetone. Acetone had a longer penetration time in the patterned PDLC film than in the planar PDLC film. In addition, acetone had a longer penetration time in the patterned PDLC film than in the planar PDLC film. Therefore, the patterned PDLC film exhibited a stronger response to acetone than the planar PDLC film. The strong response to acetone was caused by the large surface area of the patterned PDLC film. The acetone molecules had aa larger contact area on the surface and penetrate into the patterned PDLC film rather than the surface of the planar PDLC film because the former exhibits a stronger response to acetone than the latter. Therefore, acetone had a longer volatilization time in the patterned PDLC film than in the planar PDLC film.

The blue line in Figure 6 presents the time-dependent transmittance curve $T(t)$ of the patterned PDLC film with a thickness of $25 \mu \mathrm{m}$ that was exposed to acetone. When the penetration of acetone into film was greater than the volatilization of acetone, the transmittance of the patterned PDLC film decreased from its initial value of $68.9 \%$ to a minimum value of $51.1 \%$ in a short duration from $t=0 \mathrm{~s}$ to $\mathrm{t}=4 \mathrm{~s}$. The scattering of the PDLC film resulted in a difference in transmittance of $17.8 \%$. Subsequently, the volatilization of acetone was more significant than the penetration of acetone, and the transmittance increased from the minimum value to the initial value in a long duration from $t=4 \mathrm{~s}$ to $\mathrm{t}=19 \mathrm{~s}$. The time for the decrease/increase in the transmittance from the initial/minimum value to the minimum/initial value was $4 / 15 \mathrm{~s}$, which was named the penetration/volatilization time of acetone. The green line in Figure 6 presents the time-dependent transmittance curve $T(t)$ of the planar PDLC film with a thickness of $25 \mu \mathrm{m}$ that was exposed to acetone. From the comparison between the blue line and the green line in Figure 6, the patterned PDLC film had a larger change in the transmittance than the 
planar PDLC film in the penetration time. Therefore, the patterned PDLC film exhibited a stronger response to acetone than the planar PDLC film.

From the comparison between the red line and the blue line in Figure 6, it can be clearly seen that the PDLC film with $25 \mu \mathrm{m}$ thickness was thinner, resulting in a weak light scattering response to acetone and a short response time, which makes it difficult to identify organic solvents. The PDLC film with $50 \mu \mathrm{m}$ thick was thicker, and the light scattering response of the film was more significant than that of the blue line in Figure 6. Therefore, the following measurement experiments all used a $50-\mu \mathrm{m}$ thick spacer to prepare the PDLC film.

Figure 7a presents the time-dependent transmittance curves of 50- $\mu \mathrm{m}$-thick patterned PDLC films that were exposed to acetone solutions with concentrations of $25 \mathrm{v} \%, 30 \mathrm{v} \%$, $35 \mathrm{v} \%, 40 \mathrm{v} \%, 45 \mathrm{v} \%, 50 \mathrm{v} \%, 75 \mathrm{v} \%$, and $100 \mathrm{v} \%$. The patterned PDLC film had a constant transmittance at the $30 \mathrm{v} \%$ acetone solution. Therefore, the limit of detection (LOD) of $50-\mu \mathrm{m}$-thick patterned PDLC film was $35 \mathrm{v} \%$ in this work. The transmittance change of a patterned PDLC film was used to evaluate the response of the film to an organic solvent and was defined as $\left(T_{\mathrm{i}}-T_{\mathrm{m}}\right)$, where $T_{\mathrm{i}}$ and $T_{\mathrm{m}}$ were the initial and the minimum transmittances of the film. Figure $7 \mathrm{~b}$ displays the transmittance changes of the $50-\mu \mathrm{m}$-thick patterned PDLC films at the acetone solutions with the various concentrations. The transmittance changes of the patterned PDLC films were larger than zero as the concentrations of the acetone solutions exceeded $30 \mathrm{v} \%$. Therefore, the $50-\mu \mathrm{m}$-thick patterned PDLC films had an LOD of $35 \mathrm{v} \%$ in this work.
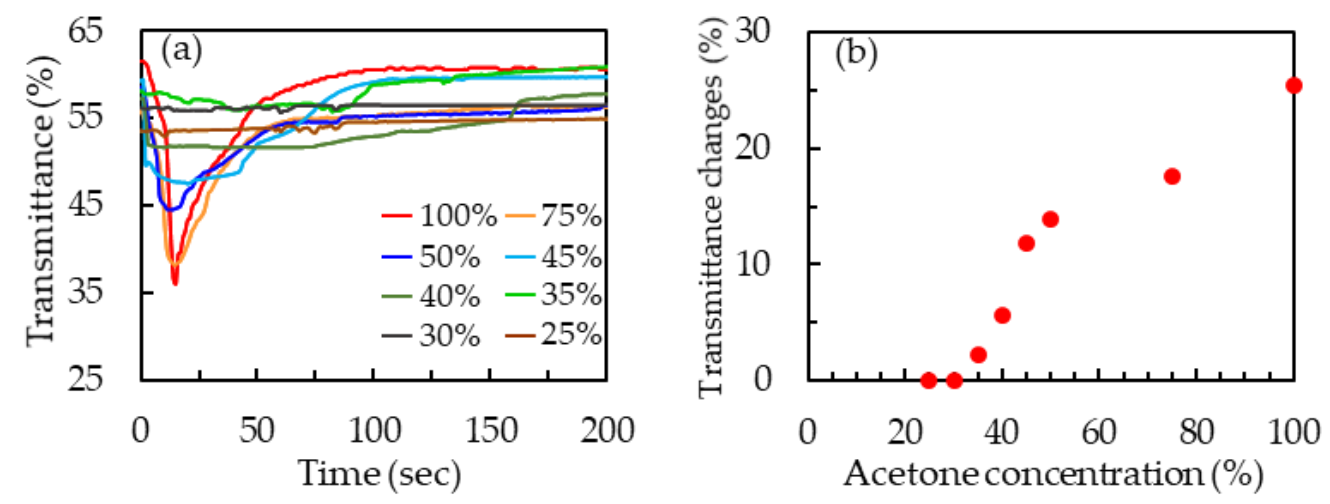

Figure 7. (a) Time-dependent transmittance curves of 50- $\mu$ m-thick patterned PDLC films that were exposed to acetone solutions with concentrations of $25 \mathrm{v} \%, 30 \mathrm{v} \%, 35 \mathrm{v} \%, 40 \mathrm{v} \%, 45 \mathrm{v} \%, 50 \mathrm{v} \%, 75 \mathrm{v} \%$, and $100 \mathrm{v} \%$. (b) Transmittance changes of 50- $\mu \mathrm{m}$-thick patterned PDLC films at acetone solutions with various concentrations.

Besides acetone, 50- $\mu \mathrm{m}$-thick patterned PDLC films were used to detect ethanol, toluene, n-butanol, and water. Figure 8 presents the time-dependent transmittance curves $T(t)$ of the 50- $\mu \mathrm{m}$-thick patterned PDLC films that were exposed to acetone, ethanol, toluene, n-butanol, and water. When the patterned PDLC film had just been exposed to organic solvents, the penetration of organic solvents prevailed over the volatilization of organic solvents. The disturbance of organic solvents caused the orientation of LC molecules to be disordered. The transmittance decreased due to scattering of the PDLCs. Subsequently, the volatilization of organic solvents was more significant than the penetration of organic solvents, and therefore the transmittance increased. However, the patterned PDLC film did not generate any response to water. Until the end of the experimental measurement, the water droplets remained on the surface of the PDLC film. 


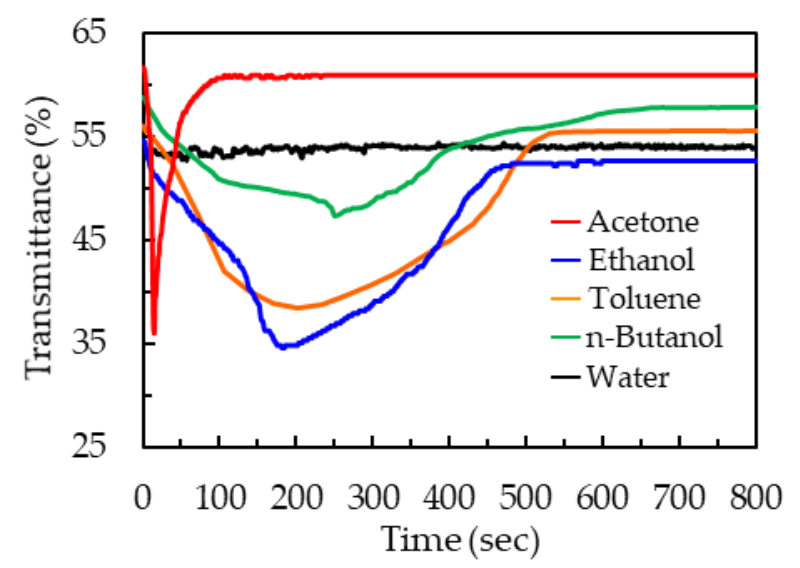

Figure 8. Time-dependent transmittance curves of the patterned PDLC films that were exposed to acetone, ethanol, toluene, n-butanol, and water.

Table 1 displays the comparison of the 50- $\mu$ m-thick patterned PDLC films that were exposed to acetone, ethanol, toluene, $\mathrm{n}$-butanol, and water. The experimental data in Table 1 were obtained from Figure 8. Table 1 reveals the response of the patterned films to the organic solvents according to their transmittance changes and penetration times of Figure 8: acetone >> ethanol >> toluene >> n-butanol. The experimental data in Table 1 reveal that the patterned PDLC film can be used to detect organic solvents and that it has potential in sensing organic gases.

Table 1. Comparison of the patterned PDLC films with a thickness of $50 \mu \mathrm{m}$ that were exposed to acetone, ethanol, toluene, n-butanol, and water.

\begin{tabular}{lccc}
\hline & Penetration Times (s) & Volatilization Times (s) & Transmittance Changes (\%) \\
\hline Acetone & 15 & 81 & 25.4 \\
\hline Ethanol & 185 & 296 & 19.8 \\
\hline Toluene & 202 & 339 & 17.5 \\
\hline n-Butanol & 250 & 418 & 11.4 \\
\hline Water & - & - & - \\
\hline
\end{tabular}

\section{Conclusions}

This study successfully produced a PDLC film that can be used to detect organic solvents. The results show that the pillar structure of the PDLC film surface can increase the surface area and promote detection efficiency to organic solvents. From the difference of the light scattering intensity and response time of the patterned PDLC film to various organic solvents, it can be used as an index to identify different organic solvents. The patterned PDLC film has the potential to be used in detecting various organic solvents or organic gases in the future.

Author Contributions: Conceptualization, C.-Y.H. and S.-H.L.; methodology, C.-Y.H.; validation, C.-Y.H. and S.-H.L.; formal analysis, S.-H.L.; investigation, C.-Y.H. and S.-H.L.; resources, C.-Y.H. and S.-H.L.; data curation, C.-Y.H. and S.-H.L.; writing—original draft preparation, S.-H.L.; writingreview and editing, C.-Y.H. and S.-H.L.; visualization, S.-H.L.; project administration, C.-Y.H. and S.-H.L.; funding acquisition, C.-Y.H. and S.-H.L. All authors have read and agreed to the published version of the manuscript.

Funding: This work was supported by the Ministry of Science and Technology (MOST) in Taiwan with Contract No. MOST 109-2112-M-040-001-MY2 and MOST 110-2112-M-029-005.

Institutional Review Board Statement: Not applicable.

Informed Consent Statement: Not applicable. 
Data Availability Statement: The data presented in this study are available on request from the corresponding author.

Conflicts of Interest: The authors declare no conflict of interest.

\section{References}

1. Lin, S.H.; Huang, B.Y.; Li, C.Y.; Yu, K.Y.; Chen, J.L.; Kuo, C.T. Electrically and optically tunable Fresnel lens in a liquid crystal cell with a rewritable photoconductive layer. Opt. Mater. Express 2016, 6, 2229-2235. [CrossRef]

2. Lin, S.H.; Li, C.Y.; Kuo, C.T.; Yeh, H.C. Fresnel lenses in $90^{\circ}$ twisted-nematic liquid crystals with optical and electrical controllability. IEEE Photon. Technol. Lett. 2016, 28, 1462-1464. [CrossRef]

3. Lin, S.H.; Huang, L.S.; Lin, C.H.; Kuo, C.T. Polarization-independent and fast tunable microlens array based on blue phase liquid crystals. Opt. Express 2014, 22, 925-930. [CrossRef]

4. Ren, H.; Fan, Y.H.; Wu, S.T. Liquid-crystal microlens arrays using patterned polymer networks. Opt. Lett. 2004, 29, 1608-1610. [CrossRef] [PubMed]

5. Lu, S.Y.; Chien, L.C. Electrically switched color with polymer-stabilized blue-phase liquid crystals. Opt. Lett. 2010, 35, 562-564 [CrossRef] [PubMed]

6. Lin, Y.H.; Chen, H.S.; Lin, H.C.; Tsou, Y.S.; Hsu, H.K.; Li, W.Y. Polarizer-free and fast response microlens arrays using polymerstabilized blue phase liquid crystals. Appl. Phys. Lett. 2010, 96, 113505. [CrossRef]

7. Xu, M.; Zhou, Z.; Ren, H.; Hee Lee, S.; Wang, Q. A microlens array based on polymer network liquid crystal. J. Appl. Phys. 2013, 113, 053105. [CrossRef]

8. Doane, J.W.; Vaz, N.A.; Wu, B.G.; Žumer, S. Field controlled light scattering from nematic microdroplets. Appl. Phys. Lett. 1986, 48, 269-271. [CrossRef]

9. Fuh, A.Y.G.; Chen, C.C.; Liu, C.K.; Cheng, K.T. Polarizer-free, electrically switchable and optically rewritable displays based on dye-doped polymer-dispersed liquid crystals. Opt. Express 2009, 17, 7088-7094. [CrossRef] [PubMed]

10. Drzaic, P.S. Polymer dispersed nematic liquid crystal for large area displays and light valves. J. Appl. Phys. 1986, 60, 2142-2148. [CrossRef]

11. Sheraw, C.D.; Zhou, L.; Huang, J.R.; Gundlach, D.J.; Jackson, T.N.; Kane, M.G.; Hill, I.G.; Hammond, M.S.; Campi, J.; Greening, B.K.; et al. Organic thin-film transistor-driven polymer-dispersed liquid crystal displays on flexible polymeric substrates. Appl. Phys. Lett. 2002, 80, 1088-1090. [CrossRef]

12. Cong, S.; Cao, Y.; Fang, X.; Wang, Y.; Liu, Q.; Gui, H.; Shen, C.; Cao, X.; Kim, E.S.; Zhou, C. Carbon nanotube macroelectronics for active matrix polymer-dispersed liquid crystal displays. ACS Nano 2016, 10, 10068-10074. [CrossRef]

13. Yu, J.H.; Chen, H.S.; Chen, P.J.; Song, K.H.; Noh, S.C.; Lee, J.M.; Ren, H.; Lin, Y.-H.; Lee, S.H. Electrically tunable microlens arrays based on polarization-independent optical phase of nano liquid crystal droplets dispersed in polymer matrix. Opt. Express 2015, 23, 17337-17344. [CrossRef] [PubMed]

14. Ren, H.; Lin, Y.H.; Fan, Y.H.; Wu, S.T. Polarization-independent phase modulation using a polymer-dispersed liquid crystal. Appl. Phys. Lett. 2005, 86, 141110. [CrossRef]

15. Song, M.; Seo, J.; Kim, H.; Kim, Y. Ultrasensitive multi-functional flexible sensors based on organic field-effect transistors with polymer-dispersed liquid crystal sensing layers. Sci. Rep. 2017, 7, 2630. [CrossRef]

16. Edwards, R.S.; Ward, J.; Zhou, L.Q.; Trushkevych, O. The interaction of polymer dispersed liquid crystal sensors with ultrasound. Appl. Phys. Lett. 2020, 116, 044104. [CrossRef]

17. Zhang, M.; Zheng, J.; Gui, K.; Wang, K.; Guo, C.; Wei, X.; Zhuang, S. Electro-optical characteristics of holographic polymer dispersed liquid crystal gratings doped with nanosilver. Appl. Opt. 2013, 52, 7411-7418. [CrossRef]

18. De Sio, L.; Lloyd, P.F.; Tabiryan, N.V.; Bunning, T.J. Hidden gratings in holographic liquid crystal polymer-dispersed liquid crystal films. ACS Appl. Mater. Interfaces 2018, 10, 13107-13112. [CrossRef]

19. Ohm, C.; Brehmer, M.; Zentel, R. Liquid crystalline elastomers as actuators and sensors. Adv. Mater. 2010, $22,3366-3387$. [CrossRef] [PubMed]

20. Lee, C.R.; Lin, S.H.; Guo, C.H.; Chang, S.H.; Mo, T.S.; Chu, S.C. All-optically controllable random laser based on a dye-doped polymer-dispersed liquid crystal with nano-sized droplets. Opt. Express 2010, 18, 2406-2412. [CrossRef]

21. Wang, J.; Zhang, Y.; Cao, M.; Song, X.; Che, Y.; Zhang, H.; Zhang, H.; Yao, J. Platinum-scatterer-based random lasers from dye-doped polymer-dispersed liquid crystals in capillary tubes. Appl. Opt. 2016, 55, 5702-5706. [CrossRef]

22. Wang, Z.; Cao, M.; Shao, G.; Zhang, Z.; Yu, H.; Chen, Y.; Zhang, Y.; Li, Y.; Xu, B.; Wang, Y.; et al. Coherent Random Lasing in Colloidal Quantum Dot-Doped Polymer-Dispersed Liquid Crystal with Low Threshold and High Stability. J. Phys. Chem. Lett. 2020, 11, 767-774. [CrossRef] [PubMed]

23. Lee, H.K.; Kanazawa, A.; Shiono, T.; Ikeda, T.; Fujisawa, T.; Aizawa, M.; Lee, B. All-optically controllable polymer/liquid crystal composite films containing the azobenzene liquid crystal. Chem. Mater. 1998, 10, 1402-1407. [CrossRef]

24. Kurihara, S.; Masumoto, K.; Nonaka, T. Optical shutter driven photochemically from anisotropic polymer network containing liquid crystalline and azobenzene molecules. Appl. Phys. Lett. 1998, 73, 160-162. [CrossRef]

25. Kim, M.; Park, K.J.; Seok, S.; Ok, J.M.; Jung, H.T.; Choe, J.; Kim, D.H. Fabrication of microcapsules for dye-doped polymerdispersed liquid crystal-based smart windows. ACS Appl. Mater. Interfaces 2015, 7, 17904-17909. [CrossRef] [PubMed] 